\title{
Impact of COVID-19 Pandemic on Patients with Non-Communicable Disease: An Observational Cross-Sectional Study at AYUSH Set-Ups of Krishna and Darjeeling District, India
}

\author{
Roja Varanasi ${ }^{a}$ Debadatta Nayak ${ }^{a}$ Arvind Kumar $^{a}$ Gurudev Choubey ${ }^{b}$ \\ Raveendar Chinta $^{c}$ Praveen Oberai ${ }^{\mathrm{a}}$ Anil Khurana $^{\mathrm{a}}$ \\ ${ }^{a}$ Central Council for Research in Homoeopathy, Ministry of AYUSH, Institutional Area, Janakpuri, India; ${ }^{b}$ Clinical \\ Research Unit (Homoeopathy), Siliguri, India; 'Regional Research Institute(H), Dr. GGH Medial College Campus, \\ Gudivada, India
}

\section{Keywords}

AYUSH · COVID-19 · AYUSH immune boosters · India ·

Non-communicable diseases

\begin{abstract}
Objective: The objective of this study was to determine the impact of COVID-19 in patients suffering from NCDs in terms of their knowledge, awareness, perception about COVID-19, use of AYUSH immune boosters (AIB), and management of chronic condition during the pandemic. Method: During the unlock down period (October 2020), a cross-sectional study was conducted in the Krishna and Darjeeling district of Andhra Pradesh and West Bengal, India. 499 individuals suffering from at least one chronic disease were interviewed using a structured questionnaire. Logistic regression was applied to investigate the relationship of socio-demographic characteristics, AIB, and morbidity with pandemic-related care challenges. Principal component analysis was applied to minimize the dimensionality of factors related to COVID care challenges. Results: 499 individuals were surveyed. $91 \%$ identified at least three correct COVID appropriate behaviours. $92.2 \%$ considered the coronavirus to be a potential threat (mean \pm SD: $5.8 \pm 2.6$ ). $44.7 \%$ and $55.3 \%$ lived with one and 2 or more chronic conditions, respectively. Hypertension alone (27.4\%) and diabetes with hypertension (33\%) were leading presentations. Out of 499 , participants, $88.8 \%$
\end{abstract}

had at least one form of AIB. 52\% took Ars. alb. with other AIB and $40 \%$ took Ars. alb. alone. Only 9 participants were infected with COVID-19. Conclusion: In the interest of a densely populated country like India, the inclusion of simple and safe AYUSH measures is realistic, ethical, and cost-effective. AYUSH interventions as COVID-19 prophylactic and treatment as well as integrative care of chronic illnesses such as NCDs are suggested.

(c) 2022 S. Karger AG, Basel
Auswirkungen der COVID-19-Pandemie auf Patienten mit nicht übertragbaren Krankheiten: Eine Querschnitts-Beobachtungsstudie in AYUSHEinrichtungen in den Distrikten Krishna und Darjeeling, Indien

\section{Schlüsselwörter}

AYUSH · COVID-19 · AYUSH-Immunbooster · Indien · Nicht übertragbare Krankheiten

\section{Zusammenfassung}

Ziel: Mit dieser Studie sollten die Auswirkungen von COVID-19 bei Patienten mit nicht übertragbaren Krankheiten (NÜK) in Bezug auf ihr Wissen und Bewusstsein sowie die Wahrnehmung von COVID-19, die Anwendung von AYUSH-Immunboostern (AIB) und die Behandlung von 
chronischen Erkrankungen während der Pandemie ermittelt werden. Methode: Während der Öffnungsphase nach dem Lockdown (Oktober 2020) wurde in den Distrikten Krishna und Darjeeling in Andhra Pradesh und Westbengalen, Indien, eine Querschnittsstudie durchgeführt. Dafür wurden 499 Personen, die an mindestens einer chronischen Krankheit litten, mithilfe eines strukturierten Fragebogens befragt. Der Zusammenhang von soziodemografischen Merkmalen, AIB und chronischen Erkrankungen mit pandemiebedingten Behandlungsproblemen wurde mittels logistischer Regression untersucht. Es erfolgte eine Hauptkomponentenanalyse, um die Dimensionalität der Faktoren im Zusammenhang mit den pandemiebedingten Behandlungsproblemen zu minimieren. Ergebnisse: Es wurden 499 Personen befragt. 91\% gaben mindestens drei korrekte COVID-entsprechende Verhaltensweisen an. 92,2\% hielten das Coronavirus für eine potenzielle Bedrohung (Mittelwert \pm SD: 5,8 $\pm 2,6$ ). $44,7 \%$ und $55,3 \%$ hatten eine bzw. zwei oder mehr chronische Erkrankungen. Die häufigsten Krankheiten waren Hypertonie $(27,4 \%)$ und Diabetes mit Hypertonie (33\%). Von den 499 Teilnehmern verwendeten 88,8\% mindestens eine Form von AIB. 52\% nahmen Ars. alb. in Kombination mit anderen AIB und 40\% nahmen nur Ars. alb. Nur 9 Teilnehmer zogen sich eine COVID-19-Infektion zu. Schlussfolgerung: Die Einbeziehung einfacher und sicherer AYUSH-Maßnahmen ist im Interesse eines dicht besiedelten Landes wie Indien realistisch, ethisch vertretbar und wirtschaftlich. AYUSH-Maßnahmen als COVID19-Prophylaxe und -Behandlung sowie als integrative Versorgung chronischer Erkrankungen wie NÜKs werden empfohlen.

๑) 2022 S. Karger AG, Basel

\section{Introduction}

The World Health Organization designated the new coronavirus strain (SARS-COV-2) as COVID-19 and announced it to be a pandemic on March 11, 2020. It has affected 223 countries globally (until 28 February 2021), COVID-19 with cumulative cases per 100,000 people to be $1,427.30$ and $2,470,772$ deaths [1]. The risk of infection is higher in the elderly and those with pre-existing noncommunicable diseases (NCDs). Cardiovascular diseases, chronic respiratory disease (chronic obstructive pulmonary disease), diabetes, cancer, chronic kidney diseases are among the most suffered NCDs [2]. Hypertension $(16.9 \%)$ was the most prevalent comorbidity in a Chinese study on 1,590 patients, followed by diabetes (8.2\%) [3].

With 1,380 million people, India is the second-highest populated country [4]. Yet new cases and total mortality of COVID-19 are relatively low when compared to figures from many other countries [5]. India also has a high rate of patients with diabetes (10\%) and hypertension
(25\%), both of which might exacerbate the COVID-19 outcomes [6]. India has high rates of tuberculosis (193 per 100,000) and pneumonia and houses one-third of the global slum population, making it impossible for them to maintain a safe social distancing due to their compromised economic and social circumstances. With this in context, the hospitalized cases in India are numerically low when compared with countries with better population indices $[6,7]$.

Wolf et al. [8] in their study on adults with chronic conditions observed $24.6 \%$ of participants were "very worried" about getting the coronavirus, $28.3 \%$ correctly identify symptoms or $30.2 \%$ could not tell the ways to prevent infection. While Pati et al. [9] in their community based found that individuals with multimorbidity experienced significantly higher care challenges than those with a single condition with notable disruption in treatment and routine check-ups. The most frequently cited concerns were physician consultation (43\%), diagnostic services $(26 \%)$, transport (33\%), and mobility restrictions (21\%).

India is a country with medical pluralism $[10,11]$. Apart from modern medicine, the National Health Policy 2017 advocates mainstreaming the potential of AYUSH (Ayurveda, Yoga \& Naturopathy, Unani, Siddha, Sowa Rigpa, and Homoeopathy) within a pluralistic system of Integrative healthcare [12]. With government funding and organized infrastructure through the Ministry of AYUSH, research has been given ample thrust [13]. Soon after the reported outbreak of COVID-19 in China [14], on the recommendation of the different focus groups, the Ministry of AYUSH $[15,16]$ issued an advisory on the use of AYUSH immune boosters (AIB) such as Kadha, consumption of golden milk (Ayurveda), Arsenicum album 30C(Homoeopathy) (Ars. alb.), herbal decoction (Unani), and practising Yoga to prevent COVID-19. India has launched its National Program for prevention and control of cardiovascular diseases, diabetes, cancer, and stroke (NPCDCS) in the year 2008, and later in the year 2015, the Ministry of AYUSH with its research councils collaborated and integrated with the Ministry of Health and Family Welfare, Govt. of India for screening, behavioural modification, treatment of people suffering from the identified NCDs covering 6 six districts across the country: three for Ayurveda, two for Homoeopathy, and one for Unani system of Medicine [17].

Homeopathy along with Yoga was implemented at two districts: Krishna District, Andhra Pradesh and Darjeeling District, West Bengal. In these districts, $16 \mathrm{AY}$ USH Lifestyle disorder clinics (ALSDC) were established at different healthcare levels such as district hospital/area hospital/rural hospital/community health centres. This present survey was undertaken on people suffering from NCDs and visiting these ALSDC to determine the impact of COVID-19 in managing their conditions during the
96

Complement Med Res 2023;30:95-106 DOI: $10.1159 / 000521904$
Varanasi/Nayak/Kumar/Choubey/Chinta/ Oberai/Khurana 
pandemics, their current awareness, assessment of the seriousness of its threat, level of worry and concern related to contracting the virus, effect on a daily routine or existing plans, management of chronic conditions, usage of AIB and if affected with COVID-19 and their recovery.

\section{Material and Methods}

Study Design, Setting, and Participants

This cross-sectional study was conducted on the patients visiting ALSDC at Krishna and Darjeeling district for management of NCDs with Homeopathy, Lifestyle modification, and Yoga. As of September 30, 2020, these states had reported 35,312 cases, including 3,234 active, and 550 fatalities [18]. Patients aged 18 years and above participated in the study. It was conducted between 5 and 15 October 2020 (during the first wave), the time corresponding to the unlock down phase enquiring the knowledge, concern, bout COVID-19, about AIB and COVID care challenges during the past 12 weeks. The reporting in the paper follows STROBE guidelines for observational studies [19].

\section{Sample Size and Sampling}

A convenient sample of at least 30 patients per ALSDC totalling 499 patients for 16 ALSDC was assumed. The primary reason for such convenient sampling was the low-resource cost and feasibility, easing out potential data collection challenges at the pandemic time. The patients who were already enrolled in the integrated National NPCDCS project were contacted either over telephone or face-to-face interviews.

\section{Data Collection Tool and Technique}

A hybrid strategy that included both face-to-face (through written informed consent) and telephonic interview (verbal consent) was done as per the feasibility. All of the interviews were conducted under the guidance of the research team. Prior training was given to the data collection team and any queries regarding the questionnaire were resolved and clarified. A structured questionnaire was developed following the studies published by Wolf et al. [8] and Pati et al. [9]. Perceived concern for COVID-19 was evaluated by asking participants to rate, on a scale of 1-10 (1 being no threat at all and 10 being very serious), how worried are they about getting COVID-19 on a Likert scale (very worried to not worried at all) and how likely they or their relatives are going to get sick from COVID-19 on a Likert scale of very likely to not at all likely. Demonstrated knowledge of COVID-19 was assessed through open-ended questions asking participants to name 3 symptoms of the coronavirus and 3 actions that the government has recommended that they could take to avoid becoming infected. Knowledge, intake, and perceived attitude towards protection through AIB on Likert scale of very likely to not at all likely were also recorded. Self-rated physical, mental, and overall health was also assessed on a Likert scale of very good to very bad. The questionnaire of data collection is provided in online supplementary Appendix I (see www. karger.com/doi/10.1159/000521904 for all online suppl. material).

\section{Statistical Analysis}

The data were entered into a pre-designed spreadsheet and then transferred to SPSS ver. 20 (IBM SPSS, USA) for statistical analysis. Frequency $(n)$ and percentage (\%) were used for categorical variables and mean for quantitative variables. Associations between patient characteristics and responses to COVID-19 awareness, perceived concern, knowledge, and related behaviour items
Table 1. Sample characteristics $(n=499)$

\begin{tabular}{|c|c|}
\hline Variable & Summary value \\
\hline Mean age & $51.8 \pm 10.1$ \\
\hline \multicolumn{2}{|l|}{ Age group } \\
\hline $30-45$ years & $149(29.9)$ \\
\hline $46-60$ years & $244(48.9)$ \\
\hline 61 years and above & $106(21.2)$ \\
\hline Male:Female & $238(48): 261(52)$ \\
\hline Rural: Urban & $314(63): 185(47)$ \\
\hline \multicolumn{2}{|l|}{ Education } \\
\hline Illiterate & $73(14.6)$ \\
\hline Junior high school & $133(26.6)$ \\
\hline High school & $152(30.4)$ \\
\hline Graduate and above & $141(28.2)$ \\
\hline \multicolumn{2}{|l|}{ Family environment } \\
\hline Living along & $6(1.2)$ \\
\hline Living spouse/family & $493(99.8)$ \\
\hline \multicolumn{2}{|l|}{ Profession } \\
\hline Farmers & $85(17.0)$ \\
\hline Office job & $57(11.4)$ \\
\hline Business/self-employed & 99 (19.8) \\
\hline Homemaker/retired & $291(51.6)$ \\
\hline \multicolumn{2}{|l|}{ Morbidity } \\
\hline Single morbidity & $223(44.7)$ \\
\hline Multimorbidity & $276(55.3)$ \\
\hline \multicolumn{2}{|l|}{ Number of chronic conditions } \\
\hline 1 & $223(44.7)$ \\
\hline 2 & $227(45.5)$ \\
\hline$\geq 3$ & $49(9.8)$ \\
\hline \multicolumn{2}{|l|}{ Diseases suffered/pattern } \\
\hline Hypertension alone & $137(27.5)$ \\
\hline Diabetes alone & $75(15.0)$ \\
\hline Chronic respiratory disease alone & $16(2.6)$ \\
\hline Hypertension + diabetes & $165(33.1)$ \\
\hline Hypertension + others & $37(7.4)$ \\
\hline Hypertension + diabetes + others & $37(7.4)$ \\
\hline Other combinations & $35(7.0)$ \\
\hline
\end{tabular}

were then examined in bivariate analyses using $\chi^{2}$ tests, $t$ tests, or analysis of variance, as appropriate. Principal component analysis was applied to transform seven co-related variables, which assessed routine care challenges during the pandemic into a smaller number of uncorrelated variables through the projection of eigenvectors of co-variance followed the method by Pati et al. [9]. AIB intake pattern was also estimated and graphically depicted. Logistic regression was undertaken to analyse the association of sociodemographic characteristics and multimorbidity status with care challenges; odds ratio, adjusted odds, 95\% confidence interval for the association, and $p$ value for the significance were obtained. Self-rated physical, mental, and overall health was assessed for multimorbidity and AIB using binary logistic regression. A $p$ value of $<0.05$ was considered statistically significant.

\section{Results}

Table 1 shows the sample characteristics of the respondents. A total of 499 patients participated in the survey. Among the sample collected: 314 (62.9), 185 (47.1), be- 
Table 2. Knowledge, attitudes, and self-reported behaviours towards COVID-19 and AIB

\begin{tabular}{|c|c|}
\hline Item & Summary value \\
\hline \multicolumn{2}{|l|}{ COVID-19 awareness and concern } \\
\hline Mean response about seriousness of COVID-19 threat & $5.8 \pm 2.6$ \\
\hline \multicolumn{2}{|l|}{ How worried are you about getting the COVID-19 } \\
\hline Very worried & $137(27.5)$ \\
\hline Somewhat worried & $167(33.5)$ \\
\hline A little worried & $93(18.6)$ \\
\hline Not worried at all & $102(20.4)$ \\
\hline \multicolumn{2}{|l|}{ Do you think that you will get sick from the coronavirus } \\
\hline I definitely will & $30(6)$ \\
\hline I probably will & $149(29.9)$ \\
\hline It's possible & $173(34.7)$ \\
\hline Not at all & $147(29.5)$ \\
\hline \multicolumn{2}{|c|}{$\begin{array}{l}\text { How likely do you think it is that you or someone you know may get sick from the } \\
\text { coronavirus this year? }\end{array}$} \\
\hline Very likely & $51(10.21)$ \\
\hline Somewhat likely & $222(44.5)$ \\
\hline Not that likely & $109(21.8)$ \\
\hline Not at all likely & $117(23.4)$ \\
\hline \multicolumn{2}{|l|}{ COVID-19 Knowledge } \\
\hline $\begin{array}{l}\text { At least } 3 \text { sources of information related to COVID-19 } \\
\text { Yes:No }\end{array}$ & $234(46): 265(53)$ \\
\hline \multicolumn{2}{|l|}{ Correctly identified 3 symptoms of COVID-19 } \\
\hline Yes:No & $429(86): 70(14)$ \\
\hline \multicolumn{2}{|l|}{ Correctly identified 3 prevention methods for COVID-19 } \\
\hline Yes:No & 455 (91.2):44 (8.8) \\
\hline \multicolumn{2}{|l|}{ Do you know about AIB suggested by Govt. of India } \\
\hline Yes:No & 443 (88.8\%):56 (11.2\%) \\
\hline \multicolumn{2}{|l|}{ Do you think AIB will benefit/protect you from COVID-19 } \\
\hline Very likely & $226(51.0)$ \\
\hline Somewhat likely & $195(44.0)$ \\
\hline Not at all likely /not sure & $22(5.0)$ \\
\hline \multicolumn{2}{|l|}{ Related behaviours } \\
\hline Number of AIB taken & $443(88.8)$ \\
\hline 1 & $204(46.0)$ \\
\hline 2 & $154(34.8)$ \\
\hline$\geq 3$ & $85(19.2)$ \\
\hline \multicolumn{2}{|l|}{ In general, how would you rate your overall health today } \\
\hline Very good & $60(12.0)$ \\
\hline Good & $245(49.1)$ \\
\hline Moderate & $184(36.9)$ \\
\hline Bad & $6(1.2)$ \\
\hline Very bad & $4(0.8)$ \\
\hline
\end{tabular}

longed to rural and urban areas, respectively, with a $100 \%$ consent rate. 225 (45\%) and 274 (55\%) had face-to-face interviews/telephonic interviews, respectively. The mean age of participants was 51 years with male:female is $48 \%: 52 \% .44 .7 \%$ and $55.3 \%$ lived with one and 2 or more chronic conditions, respectively. Hypertension alone (27.5\%) and diabetes with hypertension (33\%) were leading presentations.

\section{Knowledge}

The knowledge, attitude and awareness, and concern are reflected in Table 2. Participants received information about COVID-19 from television (462, 92.6\%), friends (249, 49.9\%), and newspaper (240, 48.1\%). Only 46\% received information from at least three sources. Ninety-one per cent identified at least three correct COVID-19 appropriate behaviour such as wearing a mask $(498,99.8 \%)$, social distancing $(457,91.6 \%)$, and hand washing for at least $20 \mathrm{~s}$ (421, 84.4\%). Eighty-six per cent of the participants identified at least three symptoms of COVID-19. The three most identified symptoms were fever $(461 ; 92.4 \%)$, dry cough (427; 85.6\%), and shortness of breath (327; 66.9\%). Regarding the government's suggestion about AIB, 443 (88.8\%) had knowledge about AIB (shown in Table 2). 


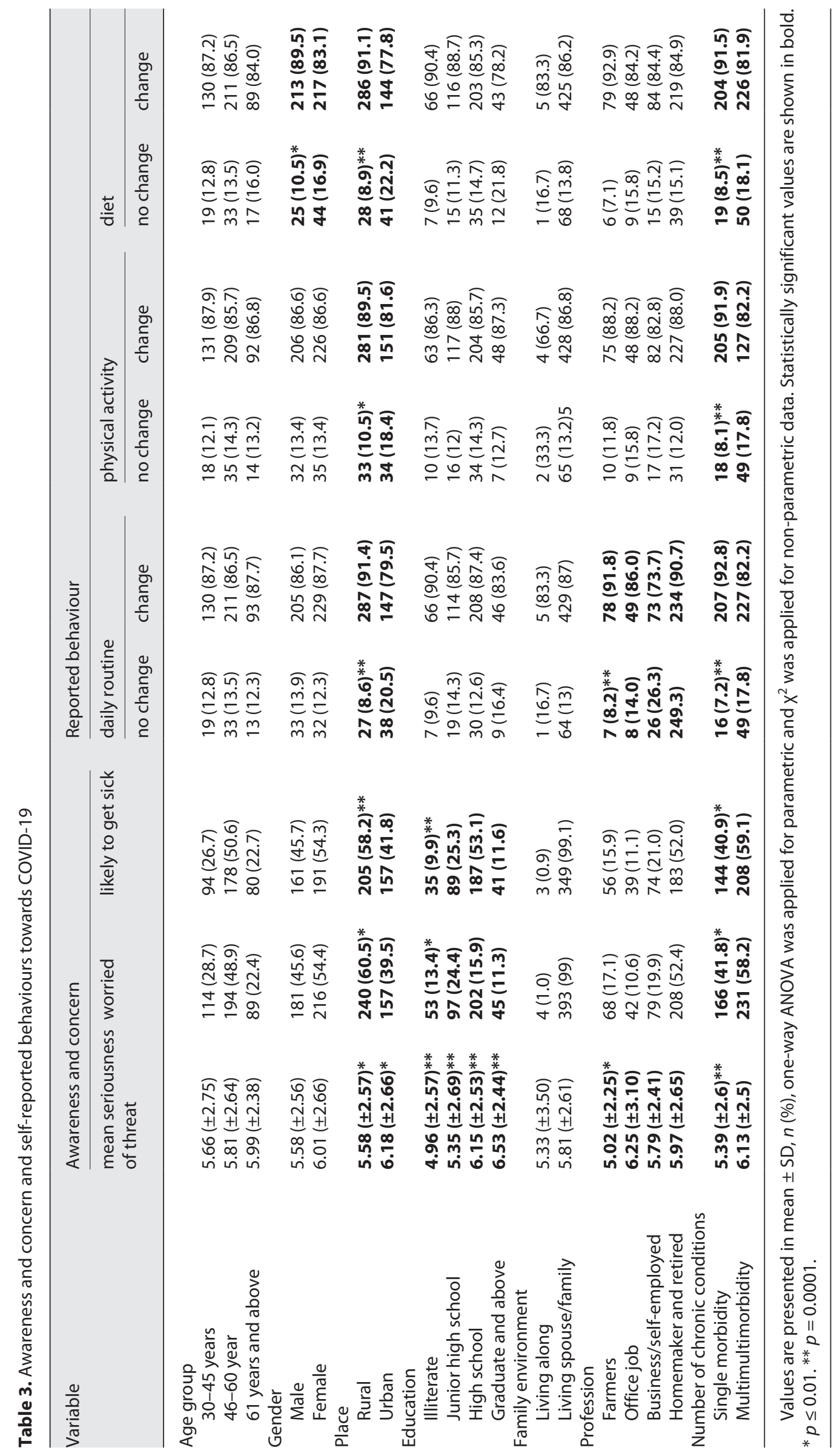


Table 4. Response to AIB

\begin{tabular}{|c|c|c|c|c|c|c|}
\hline \multirow[t]{2}{*}{ Variable } & \multicolumn{2}{|c|}{ Knowledge on AIB } & \multirow[t]{2}{*}{$x^{2} / p$ value } & \multicolumn{2}{|c|}{ Attitude towards AIB } & \multirow[t]{2}{*}{$\mathrm{x}^{2} / p$ value } \\
\hline & yes & no & & $\begin{array}{l}\text { likely to be } \\
\text { benefitted }\end{array}$ & $\begin{array}{l}\text { not } \\
\text { benefitted }\end{array}$ & \\
\hline \multicolumn{7}{|l|}{ Age group } \\
\hline $30-45$ years & $132(88.6)$ & $17(11.4)$ & \multirow[t]{3}{*}{$3.1 ; 0.207$} & $125(94.7)$ & $7(5.3)$ & \multirow[t]{3}{*}{$0.06 ; 0.970$} \\
\hline $46-60$ years & $212(86.9)$ & $32(13.1)$ & & $202(95.3)$ & $10(4.7)$ & \\
\hline 61 years and above & $99(93.4)$ & $7(6.6)$ & & $94(94.9)$ & $5(5.1)$ & \\
\hline \multicolumn{7}{|l|}{ Gender } \\
\hline Male & $212(89.1)$ & $26(10.9)$ & \multirow[t]{2}{*}{$0.04 ; 0.840$} & $201(94.8)$ & $11(5.2)$ & \multirow[t]{2}{*}{$0.04 ; 0.836$} \\
\hline Female & $231(88.5)$ & $30(11.5)$ & & $220(95.2)$ & $11(4.8)$ & \\
\hline \multicolumn{7}{|l|}{ Place } \\
\hline Rural & $271(86.3)$ & $43(13.7)$ & \multirow[t]{2}{*}{$5.19 ; 0.023$} & $257(94.8)$ & $14(5.2)$ & \multirow[t]{2}{*}{$0.05 ; 0.808$} \\
\hline Urban & $172(93.0)$ & $13(7)$ & & $164(95.3)$ & $8(4.7)$ & \\
\hline \multicolumn{7}{|l|}{ Education } \\
\hline Illiterate & $54(74.0)$ & $19(26.0)$ & \multirow[t]{4}{*}{$23.9 ; 0.0001$} & 48 (88.9) & $6(11.1)$ & \multirow{4}{*}{$8.7 ; 0.032$} \\
\hline Junior high school & $115(86.5)$ & $18(13.5)$ & & $108(93.9)$ & $7(6.1)$ & \\
\hline High school & $221(92.9)$ & $17(7.1)$ & & $216(97.7)$ & $5(2.3)$ & \\
\hline Graduate and above & $53(96.4)$ & $2(3.6)$ & & 49 (92.5) & $4(7.5)$ & \\
\hline \multicolumn{7}{|l|}{ Family environment } \\
\hline Living along & $5(83.3)$ & $1(16.7)$ & \multirow[t]{2}{*}{$0.18 ; 0.671$} & $4(80)$ & $1(20)$ & \multirow[t]{2}{*}{$2.42 ; 0.120$} \\
\hline Living spouse /family & $438(88.8)$ & $55(11.2)$ & & $417(95.2)$ & $21(4.8)$ & \\
\hline \multicolumn{7}{|l|}{ Profession } \\
\hline Farmers & $68(80)$ & $17(20)$ & \multirow[t]{4}{*}{$10.25 ; 0.017$} & $65(95.6)$ & $3(4.4)$ & \multirow[t]{4}{*}{$0.86 ; 0.834$} \\
\hline Office job & $55(96.5)$ & $2(3.5)$ & & $52(94.5)$ & $3(5.5)$ & \\
\hline Business/self-employed & $89(89.9)$ & $10(10.1)$ & & $83(93.3)$ & $6(6.7)$ & \\
\hline Homemaker and retired & $231(89.5)$ & $27(10.5)$ & & $221(95.7)$ & $10(4.3)$ & \\
\hline \multicolumn{7}{|l|}{ Number of chronic conditions } \\
\hline Single morbidity & $188(84.3)$ & 35 (15.7) & \multirow[t]{2}{*}{$8.09 ; 0.004$} & $179(95.2)$ & $9(4.8)$ & \multirow[t]{2}{*}{$0.02 ; 0.882$} \\
\hline Multimorbidity & $255(92.4)$ & $21(7.6)$ & & $242(94.9)$ & $13(5.1)$ & \\
\hline
\end{tabular}

Data presented in $n$ (\%). AIB, AYUSH immune boosters.

\section{Awareness and Concern}

Table 2 mentions the information about the awareness and concern of the participants. All the participants had heard of the coronavirus, and most (92.2\%) considered it as a potential threat (mean \pm SD: $5.8 \pm 2.6) .397(79.6 \%)$ said that they were "worried" about getting the coronavirus, and $20.4 \%$ were not worried at all. Few participants believed that they would definitely $(6 \%)$ or probably (29.9\%) get the coronavirus, whereas $34.7 \%$ and $29.5 \%$ selected possible or not getting at all, respectively. The percentage of likely getting sick with COVID-19 by the participant or one of the relatives was also similar: very likely (10.2\%), somewhat likely (44.5\%), not that likely, or not at all likely $45.2 \%$. Univariate analysis of variance (ANOVA) reflected a similar rating for the seriousness of the $\mathrm{CO}$ VID-19 threat among the age groups $(p=0.60)$ and gender $(p=0.06)$. Respondents' ratings of the seriousness significantly differed with more concern among urban residents $(p=0.01)$, with higher education (graduation and above), doing a job $(p=0.01)$, and with more than one chronic condition (multimorbidity) ( $p=0.0001)$. However, rural participants, education of high school and above and with multimorbidity were worried, and thought they would likely to get sick $(p=0.0001)$ (shown in Table 3 ).

\section{Behaviour towards AIB}

Fifty-six participants did not take any AIB. Table 4 shows association of socio-demographics and disease pattern with knowledge and attitude towards AIB. Participants residing in urban areas $(93 \%, p=0.023)$, having higher education $(96.4 \%, p=0.0001)$, office job $(96.5 \%, p$ $=0.01)$, and with multimorbidity $(92.4 \%, p=0.004)$ had knowledge about AIB. Out of 443 participants, 95\% ( $n=$ 421) believed in getting benefits from AIB. Participants who were educated had association for their belief $(p=$ $0.032)$, while no association was found among different age groups $(p=0.97)$, profession $(p=0.83)$, gender $(p=$ $0.83)$, place of residence $(p=0.80)$, suffering from single/ multimorbidity $(p=0.88)$, living alone/spouse $(p=0.12)$, and different professions $(p=0.83)$ (Table 4$)$. Out of 499 participants, $88.8 \%$ of participants had at least one form of AIB. Among them, Ars. alb. with other AIB was consumed by (52\%) and Ars. alb. alone by $40 \% .13 .9 \%$ consumed Ayurveda kadha alone or in combination with 


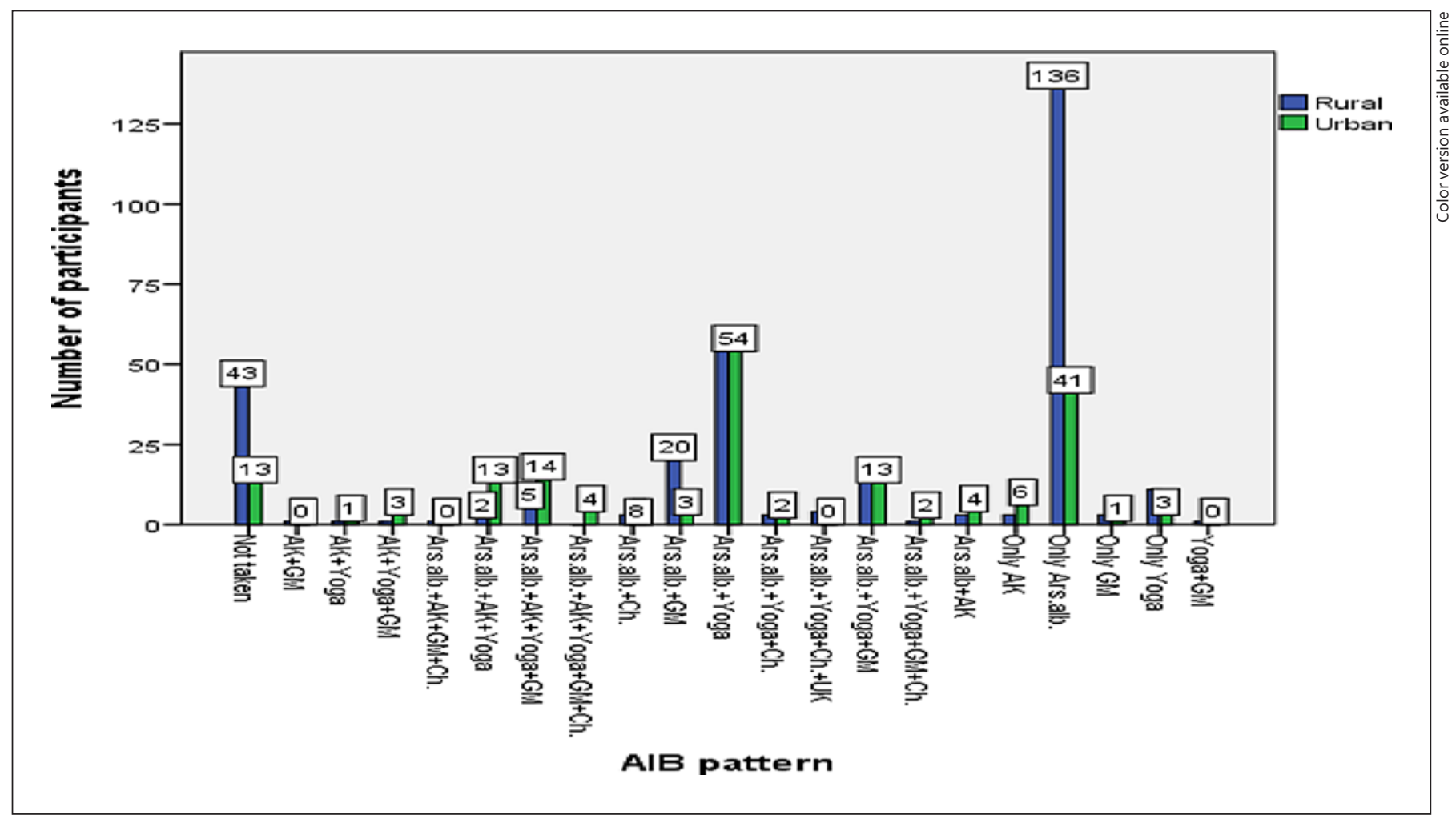

Fig. 1. Pattern of intake of AYUSH Immune boosters. AK, Ayurveda kadha; GM, Golden milk; Ch., Chwanprash; UK, Unani kadha.

Fig. 2. Scree plot of eigenvalues after principal component analysis.

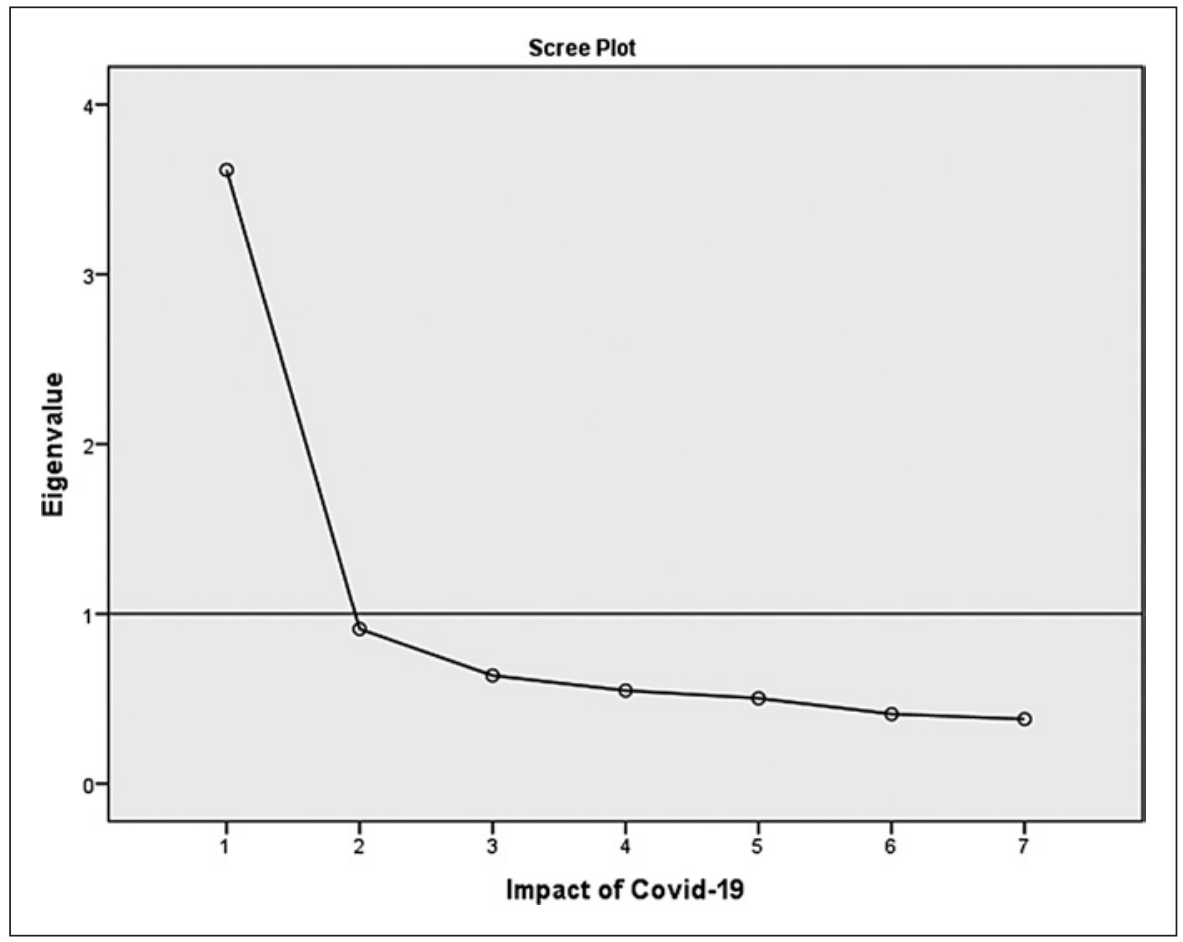

other AIB. Similarly, Yoga practice with other AIB, consumption of Golden milk with other AIB, Chyawanprash with other AIB, Unani decoction was taken by $47.5 \%$, $19.8 \%, 6.3 \%, 0.9 \%$, respectively. The pattern of AIB taken is given in Figure 1.
Challenges in Daily Routine and Chronic Care during the Pandemic

The participants reported challenges across all dimensions in the disease management behaviours in the past 12 weeks. 33\% $(n=166)$ informed that the pandemic has 


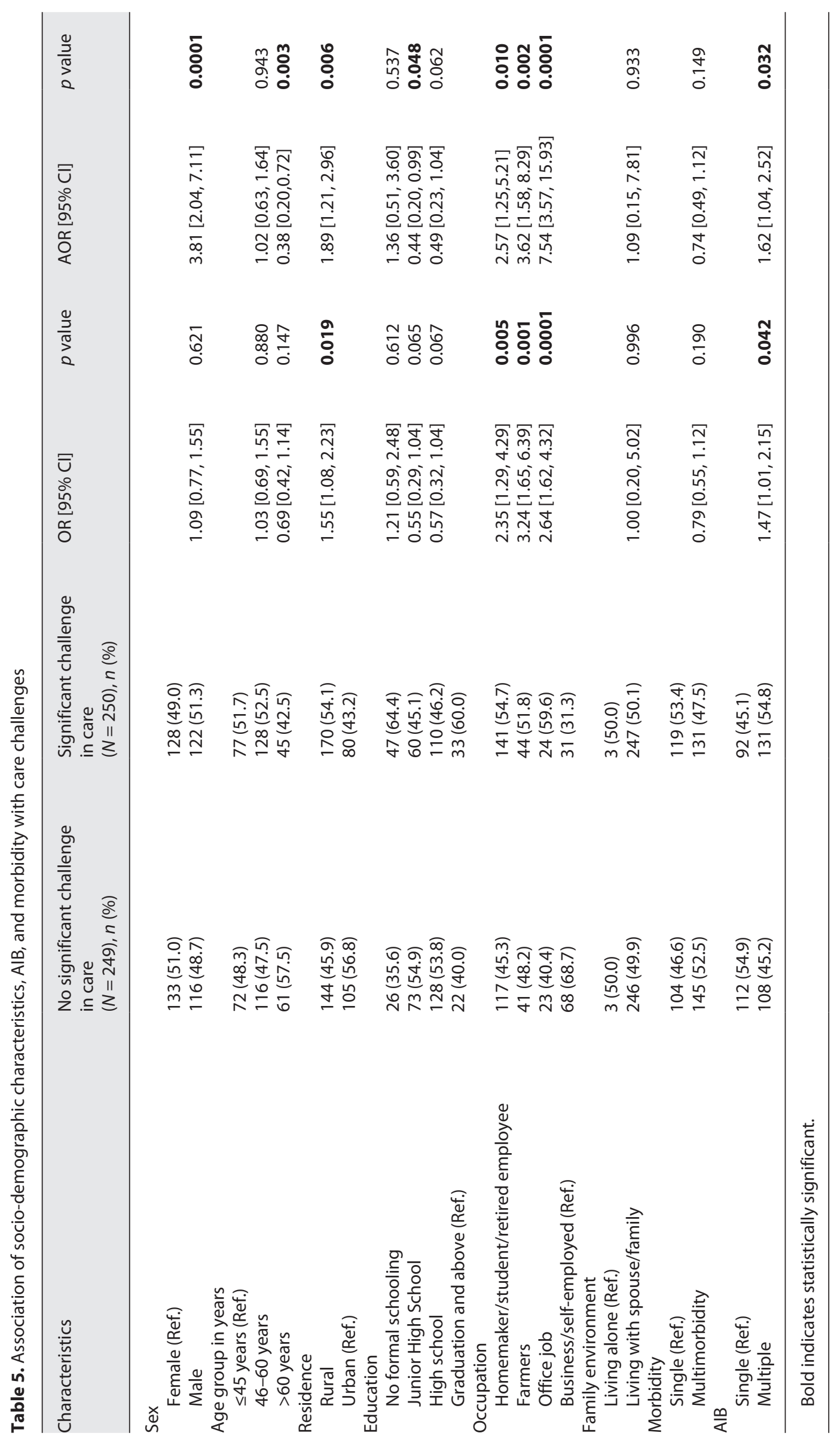


Table 6. Self-reported health

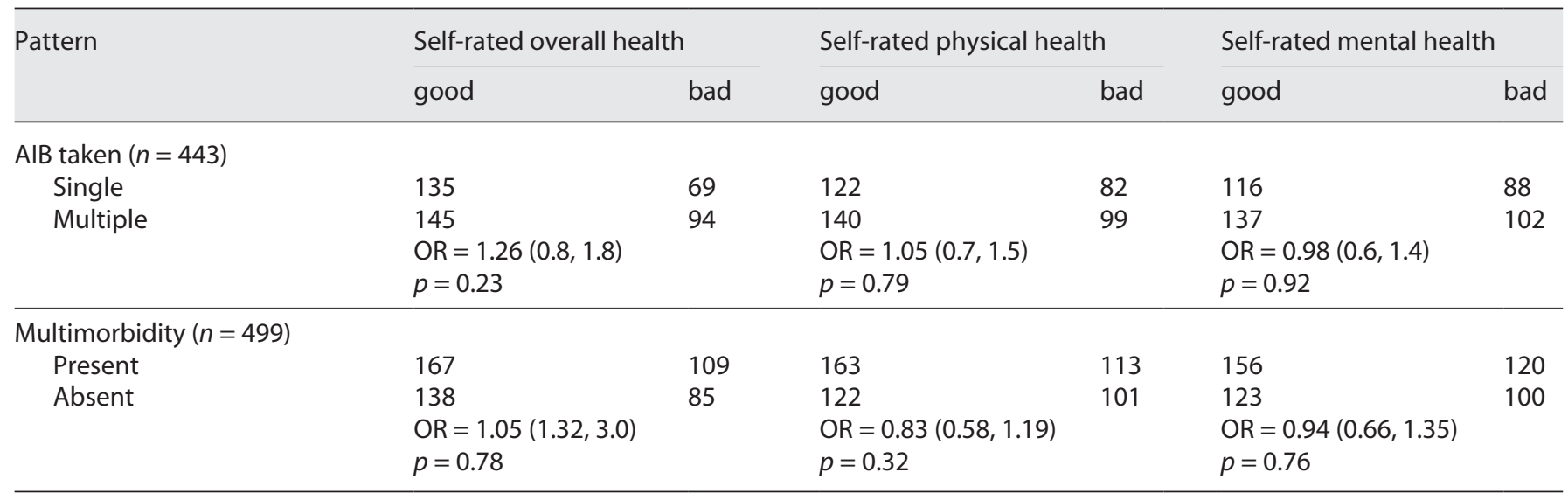

affected their long-term disease care very much and $29 \%$ $(n=146)$ reported their daily routine being affected very much. $30 \%$ reported very much changes in physical activity, $37 \%$ in the diet, $40.5 \%$ in the continuity of treatment, $45.9 \%$ reported deviations in the physician consultation, and $32.3 \%$ reported changes in their routine investigations and health check-ups (e.g., blood pressure). There was no differences among age groups $(p>0.05)$, family environment $(p>0.05)$, and education $(p>0.05)$ concerning changes in daily routine, physical activity, and diet (shown in Table 3). However, the rural participants were affected in all the dimensions compared to the urban residents $(p<0.05)$ (shown in Table 3$)$. Further with regards to their experiences during the past 12 weeks, the participants reported as follows: very much need to consult a doctor (29.3\%), very much need to visit a hospital $(31.3 \%)$, very much difficulty in getting the medicine $(45.1 \%)$, very much difficulty in getting investigations done $(30.7 \%)$, very much difficulty in day care procedures like physiotherapy, dialysis, etc. (37.1\%), very much difficulty in getting emergency care $(38.5 \%)$, difficulty in reaching a hospital or day care $(34.5 \%)$.

After principal component analysis, out of 499 participants, 250 (50.2\%) participants were found to have care challenges having above the median value, and 249 (49.8\%) had below or equal to median scores. An eigenvalue for each component was presented in the screen plot (Fig. 2). Components with eigenvalues more than 1 were extracted. The first component explains $51.6 \%$ of total variance; when considering the first two components, the cumulative variance was $64 \%$ (online suppl. Appendix II).

The association of socio-demographic characteristics, AIB and morbidity conditions with care challenges during the pandemic, is presented in Table 5. The male respondents reported greater care challenges than females (51.3\% vs. $49.0 \%)$. The perceived care challenges were significantly higher among age group $46-60$ years (52.5\%), rural dwellers (54.1\%), no formal schooling (64.4\%), office going people (59.6\%), and residing alone or separately from family members (50\%). On univariate logistic regression, rural residents $(\mathrm{OR}=1.55)$, homemakers/retired employee/students (OR: 2.35), farmers (OR: 3.24), office jobs (OR: 2.64), and taking Multiple AIB (OR = 1.47) were found to have significant care challenges. Similar findings were seen in multivariable regression with the probability of reporting care challenges being higher in males than their female counterparts $(\mathrm{AOR}=3.80,95 \%$ $\mathrm{CI}=2.04,7.10, p=0.0001)$ and with different professions. Individuals taking multiple AIB were more likely to have significant care challenges than those who had single AIB $(\mathrm{AOR}=1.62,95 \% \mathrm{CI}=1.04,2.52, p=0.032)$.

\section{Overall Health}

The self-rated overall health was very good $(12 \%, n=$ $60)$, good $(49.1 \%, n=245)$, moderate $(36.9 \%, n=184)$, bad $(1.2 \%, n=6)$, and very bad $3(0.6 \%)$. Further, the participants who took either single AIB or multiple AIB showed no significant association in either overall $(\mathrm{OR}=$ $1.26, p=0.23)$, physical $(\mathrm{OR}=1.05, p=0.79)$, or mental health $(\mathrm{OR}=0.98, p=0.92)$ (shown in Table 6). There was no difference in their self-rated health depending on their morbidity status $(\mathrm{OR}=1.05[1.3,3.0])$ for overall health and is similar for physical and mental health (shown in Table 6). Out of 499 participants, only 9 got infected with COVID-19 among these 8 were symptomatic and 1 was asymptomatic. All the positive cases with each 3 of them were treated in-home, quarantine centre, and hospital, respectively. Four participants recovered fully healthy and 4 recovered with some sort of sequelae. Three participants had taken single AIB (01 Ayurvedic Kadha, 02 Ars. alb. 30) and three had Multiple AIB (01 Ars. alb. + Yoga + Golden Milk, 01 Ars. alb. + Golden Milk, 01 Ars. alb. + Chwanprash). All the participants recovered, and no death was reported. 


\section{Discussion}

COVID-19 pandemic has created new obstacles for healthcare care providers with implications for patient care particularly for people living with NCDs. This crosssectional survey conducted during the un-lockdown period on 499 adults with chronic health conditions determined their knowledge, concern, behaviour about COVID-19 and intake of AIB propagated by Ministry of AYUSH, Govt. of India. The respondents viewed the COVID-19 outbreak to be of serious concern. Wolf et al. [8] in their study found the rating of threat to be $9 \pm 1.7$ whereas in this study the rating was $5.8 \pm 2.6$. The study shows that $79.6 \%$ are worried about the COVID-19 disease which is similar to the findings of Wolf et al. [8] at $87 \%$. This may be due to the timing of the study in India, i.e., during the unlock down period wherein more awareness was created due to the Indian government's wide circulation and awareness drive about the pandemic.

According to Gummidi et al. [20] study on the continuum of care for NCDs during the COVID-19 pandemic in rural India, $68 \%$ of the participants had adequate knowledge of symptoms of COVID-19, while $43 \%$ were not aware of the mode of transmission of the virus. In this study, $86 \%$ correctly identified at least 3 symptoms and $91 \%$ identified 3 methods of prevention. This may be due to the period of surveying with temporal effect. Multimorbidity was prevalent in 55.3 per cent of the respondents who suffered from two or more diseases. The prevalence is similar to the findings of Pati et al. [9].

Accessing essential healthcare has been challenging in many places in India as the public transport system has not been available for patients as well as for healthcare workers to access health facilities [21]. Pati et al. [9] in their study reported different challenges of people suffering from NCDs such as physician consultation (43\%) followed by diagnostic investigations (26\%), transport logistics $(33 \%)$, financial arrangements $(26 \%)$, mobility restrictions (21\%), and fear of going to hospital owing to the risk of contagion (18\%). In our study, though conducted during unlock down period had similar findings such as physician consultation (29.3\%), visiting a hospital (31.3\%), getting the medicine (45.1\%), getting investigations done $(30.7 \%)$, difficulty in daycare procedures like physiotherapy, dialysis, etc. (37.1\%), difficulty in getting emergency care (38.5\%), difficulty in reaching a hospital or daycare (34.5\%). These findings reflect the persistence of fear towards the COVID-19 disease.

The burden of NCDs in general and multimorbidity in particular can be leveraged through AYUSH systems, and a strategy to tackle this global burden is urgently needed. Building human resources for health has been an important domain in resource-poor settings [22]. With the public health advisory by Ministry to promote AYUSH med- icines as immune boosters [23] health personnel at the state level campaigned and distributed AIB. Wide advisory through television, radio, and social media created awareness among the masses for the consumption of AIB. From the sample of $499,88.8 \%$ of the participants knew AIB. Among them, $95 \%$ of the participants informed likely to benefit from taking it to protect themselves from COVID-19. 443 participants had taken AIB and the most frequently used AIB was Ars. alb. either in single (40\%) or in combination (52\%) with other AIBs. This survey also evaluated the overall health of the participants who were already under AYUSH treatment. 98.2\% of participants rated their health as good, very good, or moderate whereas only $2 \%$ rated as bad or very bad. The COVID-19 pandemic has prompted the involvement of different health systems in fighting the disease. These systems were also effective in other infectious diseases such as encephalitis, thrombocytopenia due to dengue, chikungunya, influenza-like illness [24-29]. Thus, the AYUSH systems require government focus in the battles to prevent and treat different diseases [30].

\section{Future Implication and Conclusion}

AYUSH system focuses on a holistic approach in the management of disease [31]. AYUSH care utilization is higher among patients with chronic diseases [32]; however, much less is studied on multimorbidity and what constitutes "best care" for these patients. Areas for potential investigation of multimorbidity fall primarily into three categories defining and categorizing the population; developing the tools needed to explore multimorbidity and its consequences; and using these tools to investigate promising processes of care [33]. The National Health Policy 2017 advocates "medical pluralism" and reemphasizes the need for integrating AYUSH in the National Health Mission, research and education [34]. Multimorbidity will be a major problem bringing a gross health burden to a nation. Holistic treatment approaches here AYUSH systems if added can bring down the cost of care, reduce polypharmacy, and improve quality of life $[32,35]$. Pati et al. [9] stated, "The observed higher presence of multimorbidity in younger population requires tailored health advisories harnessing on digital and traditional communication with stringent compliance to COVID-19 protection measures." AYUSH systems are suggested in the integrative approach and larger public benefit [36].

\section{Conclusion}

In the interest of a densely populated country like India, the inclusion of simple and safe AYUSH measures is realistic, ethical, and cost-effective. AYUSH interven- 
tions as COVID-19 prophylactic and treatment as well as integrative care of chronic illnesses such as NCDs is suggested.

\section{Acknowledgments}

We are grateful to all study participants for their invaluable responses and cooperation. The authors are grateful to Dr. Sanghamitra Pati, Director, RMRC-ICMR for her valuable guidance in the conceptualization of the study, permission to adapt the MAQCOVID-19 questionnaire. Dr. Srikanta Kanungo, Scientist C, RMRC, ICMR, Bhuvaneswar for his expertise and help in CPA analysis. We thank our doctors, Yoga instructors at AYUSH LSD clinics at Krishna district (Dr. K.Rajesh, Dr. P. Bhaskar, Dr. S. Lokesh kumar, Dr. I. Lakshmi Deepak, Dr. G. Swathi, Dr.Ch.Aruna Sri and Dr. Asha Dasari, Dr. M. Jaya Lakshmi, Dr. S. Siva Kumar, Dr. M. Jaya Subhashini, Dr. V. Pragathi Pawan, Dr. N. Sree Hanumantha Rao, Dr. R. Jyothsna, Dr. K. Kishore, Dr. Masarath Sulthana, Dr. B. Poorna Chandra Rao, Dr. V. Dhanasree, Dr. K. Srinivasulu, and Dr. Y. Surya Narayana R.A) and Darjeeling district (Dr. Abhiram Banerjee, Dr. Indra Dev Pratap, Dr. Santosh Kumar Suman, Dr. Sabiha Rafique, Dr. Md Mostafijur Rahaman J, Dr. Sabiha Perween, Yoga Instructor Mukto Rajowar and Dhananjoy Chutia for facilitating data collection. Dr. Shashi Giri, RO(H), DRDPRCRI, Noida, Mr. Khushal Negi, Office assistant, CCRH Hqrs, for merit special appreciation and extending technical support in data curating and developing tables.

\section{Statement of Ethics}

Ethical clearance was obtained from the 24th Central Ethics Committee of Central Council for Research in Homoeopathy (Ref. No.1-3/2019-20/CCRH/Tech./24EC/2493 dated 24 September
2020). Necessary measures were taken to ensure confidentiality and anonymity of patients. The study registered at CTRI-IndiaCTRI/2020/09/028132.

\section{Conflict of Interest Statement}

The authors have no conflicts of interest to declare.

\section{Funding Sources}

There is no funding granted for this study.

\section{Author Contributions}

R.V. and D.N. conceptualized the study and final version was approved by all authors. G.C. and R.C. responsible for data collection, A.K. and R.V. conducted the statistical analysis. R.V. drafted the first version of the manuscript with relevant suggestions from D.N., G.C., R.C., P.O., A.K., and A.K. All the authors approved the version submitted for publication.

\section{Data Availability Statement}

The datasets used and/or analyzed during the current study are available from the corresponding author on reasonable request.

\section{References}

1 World Health Organization. WHO Coronavirus (COVID-19) Dashboard. [cited 2021 Aug 16]. Available from: https://covid19. who.int/?gclid=CjwKCAjwmeiIBhA6EiwAuaeFVfVhjq9xKa0Hvxye_sw8FMLKfOL23YR3U4WpDLAJy4Hcq_g9U0YgRoCO2oQAvD_BwE.

2 Wold Health Organization. The impact of the COVID-19 pandemic on noncommunicable disease resources and services: results of a rapid assessment. 2020. p. 1-32. Available from: https://www.who.int/teams/noncommunicable-diseases/covid-19.

3 Guan W, Liang W, Zhao Y, Liang H, Chen Z, $\mathrm{Li} \mathrm{Y}$, et al. Comorbidity and its impact on 1590 patients with covid-19 in China: a nationwide analysis. Eur Respir J. 2020.

4 Population total, India. [cited 2020 Sep 9]. Available from: https://data.worldbank.org/ indicator/SP.POP.TOTL?locations=IN.

5 Sethi A. What rebuttals to the lancet's editorial on India got wrong. The Wire. 2021. [cited 2021 Jul 6]. Available from: https://thewire. in/health/covid-19-india-the-lancet-editorial-rebuttals.
6 Kamath S, Kamath R, Salins P. COVID-19 pandemic in India: challenges and silver linings. Postgrad Med J. 2020;96(1137):422-3.

7 Govt. of India. India TB Report 2020: Ministry of Health and Family Welfare. 2020. [cited 2021 Apr 2]. Available from: https://tbcindia. gov.in/showfile.php?lid=3538.

8 Wolf MS, Serper M, Opsasnick L, O'Conor RM, Curtis L, Benavente JY, et al. Awareness, attitudes, and actions related to COVID-19 among adults with chronic conditions at the onset of the U.S. Outbreak: a cross-sectional survey. Ann Intern Med. 2020 Jul 21;173(2):100-9.

9 Pati S, Mahapatra P, Kanungo S, Uddin A, Sahoo KC. Managing multimorbidity (multiple chronic diseases) amid COVID-19 pandemic: a community based study from Odisha, India. Front Public Heal. 2021 Feb 1;8:584408.

10 Ruhil R. Medical pluralism in India and its integration into state health services system. Ayushdhara. 2015;2(5):309-14. Available from: https://ayushdhara.in/index.php/ayushdhara/article/view/26/76.
11 Dinges M. Medical pluralism and Homoeopathy in India and Germany (1810-2010) A comparison of practices. Franz Steiner Verlag; 2014. p. 250. Available from: https://elib r a r y . s t e i n e r - v e r l a g. d e / book/99.105010/9783515107020.

12 Shankar D, Patwardhan B. AYUSH for new India: vision and strategy. J Ayurveda Integr Med. 2017;8(3):137-9.

13 Ministry of AYUSH Government of India. Dashboard of Infrastructure. [cited 2021 Aug 19]. Available from: https://dashboard.ayush. gov.in/.

14 Huang C, Wang Y, Li X, Ren L, Zhao J, Hu Y, et al. Clinical features of patients infected with 2019 novel coronavirus in Wuhan, China. Lancet. 2020;395(10223):497-506.

15 Ministry of AYUSH. Advisory from ministry of AYUSH for meeting the challenge arising out of spread of corona virus (COVID-19) in India. 2020. p. 9. [cited 2021 Jul 7]. Available from: https://www.ayush.gov.in/docs/125.pdf.

16 Ministry of AYUSH. Ayurveda's immunity boosting measures for self care during COVID 19 crisis. 2020. [cited 2021 Jul 7]. Available from: https://www.ayush.gov.in/docs/123.pdf. 
17 Ministry of Health and Family Welfare Government of India. National programme for prevention \& Control of cancer Diabetes, Cardiovascular Diseases \& stroke (NPCDCS) National Health Mission. [cited 2021 Jul 7]. Available from: http://nhm.gov.in/index1. php?lang=1\& level=2\& sublinkid=1048\& lid $=604$.

18 Coronavirus Outbreak in India: covid19india.org. [cited 2021 Feb 20]. Available from: https://www.covid19india.org/.

19 Von Elm E, Altman DG, Egger M, Pocock SJ Gøtzsche PC, Vandenbroucke JP, et al. The strengthening the reporting of observational studies in epidemiology (STROBE) statement: guidelines for reporting observational studies. Ann Intern Med. 2007 Oct 16;147(8) 573-7.

20 Gummidi B, John O, Jha V. Continuum of care for non-communicable diseases during COVID-19 pandemic in rural India: a mixed methods study. J Fam Med Prim Care. 2020; 9(12):6012.

21 Kataria I, Jain N, Arora M. COVID19 and People living with Noncommunicable Diseases in India | ORF. Health Express. 2020. [cited 2021 Mar 17]. Available from: https:// www.orfonline.org/expert-speak/covid19. and-people-living-with-noncommunicablediseases-in-india/.

22 Ramachandran P. Human resources for health. Indian J Med Res. 2006;123:485-8.

23 Ministry of AYUSH Government of India. Advisory to recess the symptoms of respiratory tract in possible corona virus infected cases. Press Information Bureau, Government of India; 2020.
24 Oberai P, Varanasi R, Padmanabhan M, Upadhyaya A, Singh S, Singh SP, et al. Effectiveness of homeopathic medicines as add-on to institutional management protocol for acute encephalitis syndrome in children: an open-label randomized placebo-controlled trial. Homeopathy. 2018 Aug;107(3):161-71. 25 Nayak D, Nayak C, Oberai P, Padmanabhan M, Singh H, Singh V. Homoeopathic Genus Epidemicus "Bryonia alba" as a prophylactic during an outbreak of Chikungunya in India: a cluster -randomised, double -blind, placebo- controlled trial. Indian J Res Homoeopathy. 2014;8(3):160-5.

26 Nayak D, Chadha V, Jain S, Nim P, Sachdeva J, Sachdeva G, et al. Effect of adjuvant Homeopathy with usual care in management of thrombocytopenia due to dengue: a comparative cohort study. Homeopathy. 2019;108(3):150-7.

27 Chakraborty P, Lamba C, Nayak D, John M, Sarkar D, Poddar A, et al. Effect of individualized homoeopathic treatment in influenza like illness: a multicenter, single blind, randomized, placebo controlled study. Indian J Res Homoeopathy. 2013;7(1):22.

28 Mathie RT, Baitson ES, Frye J, Nayak C, Manchanda RK, Fisher P. Homeopathic treatment of patients with influenza-like illness during the $2009 \mathrm{~A} / \mathrm{H} 1 \mathrm{~N} 1$ influenza pandemic in India. Homeopathy. 2013 Jul;102(3):187-92.
29 Gundeti MS, Bhurke LW, Mundada PS, Murudkar S, Surve A, Sharma R, et al. AY USH 64, a polyherbal Ayurvedic formulation in Influenza-like illness: results of a pilot study. J Ayurveda Integr Med. 2022 Jan-Mar; 13(1):100325

30 Priya R, Sujatha V. AYUSH for COVID-19: science or superstition?. Indian J Public Health. 2020 Jun 1;64:S105-7.

31 Gopichandran V, Satish Kumar CH. Mainstreaming AYUSH: an ethical analysis. Indian J Med Ethics. 2012;9(4):272-7.

32 Rudra S, Kalra A, Kumar A, Joe W. Utilization of alternative systems of medicine as health care services in India: evidence on AYUSH care from NSS 2014. PLoS One. 2017 May 1; 12(5):e0176916.

33 Fortin M, Soubhi H, Hudon C, Bayliss EA Van Den Akker M. Multimorbidity's many challenges: time to focus on the needs of this vulnerable and growing population. BMJ. 2007;334(7602):1016-7.

34 Ministry of Health and Family Welfare Government of India. National health policy. New Delhi; 2017. [cited 2021 Feb 27]. Available from: https://nib.gov.in/National Health Policy 2017.pdf.

35 Bellavite P. Homeopathy and integrative medicine: keeping an open mind. J Med Person. 2015;13:1-6.

36 Chaturvedi S, Kumar N, Tillu G, Deshpande S, Patwardhan B. AYUSH, modern medicine and the Covid-19 pandemic. Indian J Med Ethics. 2020 Jul 30;5(3):191-5. 